Testing novel pharmacological strategies for the management of atrial fibrillation in a large animal experimental model

Summary of PhD Thesis

Viktor Juhász, $M D$

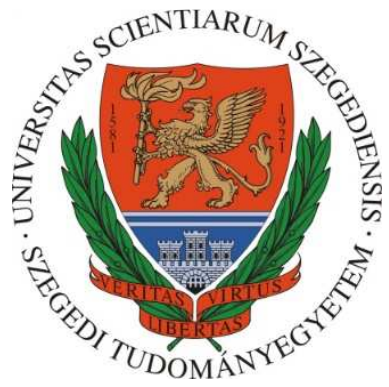

Szeged

2017 



\title{
Testing novel pharmacological strategies for the management of atrial fibrillation in a large animal experimental model
}

\author{
Summary of PhD Thesis
}

Viktor Juhász, $M D$

Supervisor:

István Baczkó, MD, PhD, habil

Department of Pharmacology and Pharmacotherapy

Faculty of Medicine, University of Szeged

Doctoral School of Multidisciplinary Medicine

University of Szeged

Szeged, Hungary

2017 


\section{LIST OF FULL LENGTH PUBLICATIONS RELATED TO THE SUBJECT OF THE THESIS}

I. Juhász V, Hornyik T, Benák A, Nagy N, Husti Z, Pap R, Sághy L, Virág $\mathrm{L}$, Varró A, Baczkó I. Comparison of the effects of $\mathrm{I}_{\mathrm{K}, \mathrm{ACh}}, \mathrm{I}_{\mathrm{Kr}}$ and $\mathrm{I}_{\mathrm{Na}}$ block in conscious dogs with atrial fibrillation and on action potentials in remodeled atrial trabeculae. CANADIAN JOURNAL OF PHYSIOLOGY AND PHARMACOLOGY, 2017, in print

IF (2016): $1.822(\mathrm{Q} 2)$

II. Baczkó I, Liknes D, Yang W, Hamming KC, Searle G, Jaeger K, Husti Z, Juhász V, Klausz G, Pap R, Sághy L, Varró A, Dolinsky V, Wang S, Rauniyar V, Hall D, Dyck JR, Light PE. Characterization of a novel multifunctional resveratrol derivative for the treatment of atrial fibrillation. BRITISH JOURNAL OF PHARMACOLOGY, 2014, 171(1): 92-106. doi: 10.1111/bph.12409.

IF (2014): 4.842 (Q1/D1)

III. Jost N, Kohajda Zs, Kristóf A, Kovács PP, Husti Z, Juhász V, Kiss L, Varró A, Virág L, Baczkó I. Atrial remodeling and novel pharmacological strategies for antiarrhythmic therapy in atrial fibrillation. CURRENT MEDICINAL CHEMISTRY, 2011, 18(24): 3675-3694. doi:10.2174/092986711796642373.

$\operatorname{IF}(2011)=4.859(\mathrm{Q} 1)$

\section{Cumulative impact factor: 11.523}

\section{OTHER FULL PUBLICATIONS}

I. Major P, Baczkó I, Hiripi L, Odening KE, Juhász V, Kohajda Zs, Horváth A, Prorok J, Seprényi Gy, Kovács M, Ördög B, Doleschall Z, Nattel S, Varró A, Bősze Zs. A novel transgenic rabbit model with reduced repolarization reserve: long QT syndrome caused by a dominant-negative 
mutation of KCNE1 gene. BRITISH JOURNAL OF PHARMACOLOGY, 2016, 173(12): 2046-2061. doi: 10.1111/bph.13500.

$\operatorname{IF}(2016)=5.491(\mathrm{Q} 1 / \mathrm{D} 1)$

II. Husti Z, Tábori K, Juhász V, Hornyik T, Varró A, Baczkó I. Combined inhibition of key potassium currents differently affects cardiac repolarization reserve and arrhythmia susceptibility in dogs and rabbits. CANADIAN JOURNAL OF PHYSIOLOGY AND PHARMACOLOGY, 2015, 93(7): 535-544. doi: 10.1139/cjpp-2014-0514.

$\operatorname{IF}(2015)=1.704(\mathrm{Q} 2)$

III. Kristóf A, Husti Z, Koncz I, Kohajda Zs, Szél T, Juhász V, Biliczki P, Jost N, Baczkó I, Papp JGy, Varró A, Virág L. Diclofenac prolongs repolarization in ventricular muscle with impaired repolarization reserve. PLOS ONE, 2012, 7(12): e53255. doi:10.1371/journal.pone.0053255. $\operatorname{IF}(2012)=3.73(\mathrm{Q} 1)$

Number of quotable abstracts: 22

Impact factor of papers related to the subject of the thesis: $\mathbf{1 1 . 5 2 3}$

Impact factor of other papers: $\mathbf{1 0 . 9 2 5}$

Total impact factor: $\mathbf{2 2 . 4 4 8}$ 


\section{ABBREVIATIONS}

$\mathrm{APD}_{25}, \mathrm{APD}_{50}, \mathrm{APD}_{90} \quad$ Action potential duration at 25,50 and $90 \%$ of repolarization

AERP

Atrial effective refractory period

AF

Atrial fibrillation

BCL

Basic cycle length

ERP

Effective refractory period

$\mathrm{I}_{\mathrm{K}, \mathrm{ACh}}$

Acetylcholine activated potassium current

$\mathrm{I}_{\mathrm{Kr}}$

Rapid component of the delayed rectifier

potassium current

$\mathrm{I}_{\mathrm{Kur}}$

Ultrarapid outwardly rectifying potassium current

$\mathrm{I}_{\mathrm{Na}}$

Voltage dependent sodium current

NFAT

Nuclear factor of activated T-cells

TdP

Torsades de Pointes chaotic ventricular tachycardia 


\section{INTRODUCTION}

Atrial fibrillation (AF) is the most frequently encountered chronic arrhythmia, associated with increased morbidity and mortality due to thromboembolic complications and concomitant heart failure. Its incidence and prevalence is rapidly increasing with the aging of the population and the number of cases will probably double by 2060 in the EU. There is a great unmet need for safer and more effective pharmacological AF therapy, since drugs currently used for rhythm control may significantly increase the risk for Torsades de Pointes arrhythmias due to their ventricular electrophysiological effects; can promote adverse vascular events; can exhibit reduced efficacy in persistent AF; and the most effective antiarrhythmic drug, amiodarone, has serious extracardiac side effects following chronic administration. In addition, as part of the pathological electrical remodeling accompanying $\mathrm{AF}$, the expression of numerous ion channels and exchangers is altered that can modify the arrhythmia substrate and increase triggered activity resulting in AF to become self-sustaining, and also significantly altering potential drug targets.

One of the possible approaches to improve pharmacotherapy of AF is the identification of drug targets ideally expressed only in atrial tissue, since atrial selective ion channel modulation would be devoid of ventricular proarrhythmic adverse effects. The $\mathrm{K}_{\mathrm{v}} 1.5$ channel that conducts the ultrarapidly activating outwardly rectifying $\mathrm{I}_{\mathrm{Kur}}$ represents such a target, since its block prolongs the atrial action potential duration (APD) and effective refractory period (ERP). However, data regarding changes in $\mathrm{I}_{\mathrm{Kur}}$ expression are inconsistent in animal experimental models of $\mathrm{AF}$ and human, with some clinical studies showing downregulation of the channel in patients with chronic AF. Another target with relative atrial selectivity is the acetylcholine-receptor activated inwardly rectifying $\mathrm{I}_{\mathrm{K}, \mathrm{ACh}}$ $\left(\mathrm{K}_{\mathrm{ir}} 3.1 / \mathrm{K}_{\mathrm{ir}} 3.4\right)$, that is found in larger amounts in the atria than in the ventricles. Importantly, in contrast to the fact that $\mathrm{I}_{\mathrm{K}, \mathrm{ACh}}$ downregulation was also observed in chronic AF, a constitutively active component of $\mathrm{I}_{\mathrm{K}, \mathrm{ACh}}$ was detected in patients with persistent AF. Therefore, $\mathrm{I}_{\mathrm{K}, \mathrm{ACh}}$ block represents a promising target for the treatment of AF. The selective inhibition of $\mathrm{I}_{\mathrm{K}, \mathrm{ACh}}$ was shown to exhibit beneficial effects against $\mathrm{AF}$ in different animal models anesthetized with a combination of isoflurane and thiopental. 
However, thiopental and isoflurane have well known ion channel modulating properties. Thiopental blocks $\mathrm{I}_{\mathrm{Ca}, \mathrm{L}}, \mathrm{I}_{\mathrm{K} 1}, \mathrm{I}_{\mathrm{Ks}}$ and isoflurane blocks $\mathrm{I}_{\mathrm{Ca}, \mathrm{L}}$ and $\mathrm{I}_{\mathrm{Ks}}$, modulates mitochondrial calcium-activated $\mathrm{K}^{+}$channels. These different effects on cardiac ion channels can profoundly influence the outcome of atrial and ventricular arrhythmia studies depending on the anesthetic used, including thiopental and isoflurane.

Given the complex aetiology of $\mathrm{AF}$, it has been suggested that drugs targeting multiple pathways involved in AF development may be more effective. Over the past fifteen years, studies on the cellular pathways in AF have revealed potential therapeutic targets to develop new antiarrhythmic drugs for AF management. In addition to the ion channels mentioned above, voltage-gated sodium channels, two-pore potassium channels, oxidative stress and activation of the transcription factor NFAT have all been implicated in AF development. To date, AF drugs have been exclusively targeted towards ion channels. However, non-ionic remodeling events are also likely to contribute to the initiation and maintenance of AF. It has been further suggested that targeting maladaptive remodeling events (,upstream therapy") in AF may also be required for effective control of AF.

\section{AIMS OF THE STUDIES}

1. To establish a large animal in vivo atrial fibrillation model in the Department of Pharmacology and Pharmacotherapy for the testing of potential novel drug candidates for AF management, and to provide remodeled atrial tissue for $\mathrm{AF}$ mechanism studies for in vitro investigations.

2. To test the effects of an atrial selective ion channel blocker in the established model on inducibility of $\mathrm{AF}$, on the duration of $\mathrm{AF}$ episodes, on the right atrial effective refractory period (AERP) in conscious dogs with $\mathrm{AF}$ and investigation of the mechanisms of action on atrial trabeculae isolated form these animals.

3. To investigate experimental compounds with multiple mechanisms of action with parallel targeting of ion channels and cellular pathways implicated in $\mathrm{AF}$ in the chronic right atrial tachypacing induced conscious dog atrial fibrillation model. 


\section{METHODS}

Ethical issues, experimental animals

The studies were conducted in compliance with the Guide for the Care and Use of Laboratory Animals (NIH Publication No. 85-23, Revised 1996), and the protocol was approved by the Ethical Committee for the Protection of Animals in Research of the University of Szeged, Hungary (I74-5-2012) and by the Department of Animal Health and Food Control of the Ministry of Agriculture (XIII/1211/2012).

Establishment of the large animal model of chronic atrial tachypacing induced $A F$ in conscious dogs in the laboratory

Male Beagle dogs weighing 12-16 kg were used for the experiments. The dogs were accommodated to experimental personnel and equipment, every day for a week before the start of the studies. The pacemaker and pacemaker electrode implantation procedures were performed under ketamine (induction: $10 \mathrm{mg} / \mathrm{kg}$ i.v., maintenance: $2 \mathrm{mg} / \mathrm{kg}$, every $20 \mathrm{~min}$ ) + xylazine (induction: $1 \mathrm{mg} / \mathrm{kg}$, maintenance: $0.2 \mathrm{mg} / \mathrm{kg}$, every $20 \mathrm{~min}$ ) anesthesia. The implantations were carried out under proper antibiotic coverage as follows: amoxicillin/clavulanic acid (1000 mg/200 mg i.v.) and gentamicin (40 mg i.v.) given before the operation, amoxicillin/clavulanic acid $(500 \mathrm{mg} / 125 \mathrm{mg}$ orally, twice a day for 5 days; Augmentin $500 \mathrm{mg} / 125 \mathrm{mg} 囚)$ given following the operation. For peri-operative analgesia metamizole sodium (1000 mg i.v., $1 \mathrm{~g} / 2 \mathrm{ml})$ and tramadol $(50 \mathrm{mg}$ i.v.) were administered. Two bipolar pacemaker electrodes (Synox SX 53JBP and Synox SX 60/15-BP) were positioned into the right atrial appendage and apex of the right ventricle, respectively, and the electrodes were connected to pacemakers (Logos DS and Philos S) in subcutaneous pockets in the neck area, followed by radiofrequency catheter ablation of the AV node. The pacemakers were programmed by the ICS 3000 Programmer (Biotronik Hungary Ltd.). Following recovery from surgery (35 days), right atrial tachypacing was started at 400 beats/min, maintained for 6 to 7 weeks before the experiments to allow electrical remodeling of the atria (monitored by the measurement of the right atrial effective refractory period (AERP) every second day). The AERPs were measured at basic cycle lengths (BCL) of 150 and $300 \mathrm{~ms}$ with a train of 10 stimuli (S1) 
followed by an extrastimulus (S2), with the AERP defined as the longest S1-S2 interval that did not produce a response.

On the day of the experiment atrial pacing was stopped, continuous recording of the electrocardiogram started using precordial leads and the AERP was measured. A control set (25 times) of 10-second-long rapid atrial bursts ( 800 beats/min, at twice threshold) were performed in order to induce atrial fibrillation in conscious dogs preceded by a bolus infusion of vehicle in $15 \mathrm{~min}$. Following the measurement of AERP, additional sets of atrial bursts (25-25 times) were applied subsequent to either tertiapin-Q (Tocris Bioscience, $18 \mu \mathrm{g} / \mathrm{kg}$ then $56 \mu \mathrm{g} / \mathrm{kg}$ ), or dofetilide (Sigma-Aldrich, 25 $\mu \mathrm{g} / \mathrm{kg}$ ), or propafenone (RYTMONORM, $0.3 \mathrm{mg} / \mathrm{kg}$ then $1 \mathrm{mg} / \mathrm{kg}$ ) i.v. administration. At least 4 days were allowed for washout between in vivo experiments with different compounds.

In another set of experiments (on other PM-instrumented animal group), similarly performed tests were done in order to measure the in vivo effects of Compound 1. In those tests the bolus infusion of vehicle was $20 \mathrm{~mL}$ of a mixture of DMSO + $\beta$-hydroxypropyl-cyclodextrin + saline (all from Sigma-Aldrich), and during the control 25 bursts and subsequent AF episodes, a continuous infusion of vehicle was maintained (in a volume of $1.7 \mathrm{~mL} / \mathrm{kg} / \mathrm{min}$ ). Following the measurement of AERP, Compound 1 (C1) was infused in a dose of $0.3 \mathrm{mg} / \mathrm{kg}$ (in $15 \mathrm{~min}$ bolus + maintenance) and $\mathrm{AF}$ was again induced 25 times. An identical procedure was repeated in every dog with $1 \mathrm{mg} / \mathrm{kg}$ dose of $\mathrm{C} 1$. All intravenous infusions were performed using a programmable infusion pump (Terufusion TE-3, Terumo Europe, Leuven, Belgium). The ECG was recorded using precordial leads, was digitized and stored on a computer for off-line analysis using SPEL Advanced Haemosys software (version 3.2, MDE Heidelberg GmbH). The incidence of $\mathrm{AF}$, the total duration of $\mathrm{AF}$, the average duration of $\mathrm{AF}$ episodes were measured and calculated along with changes in AERP and QT interval. QT intervals were measured on dogs with pacemaker implantation before the $12^{\text {th }}$ burst and were not corrected for heart rate since QT measurements were made at the heart rate set to 80 beats/min by the ventricular pacemaker. Experiments were performed in freely moving conscious dogs so that any effects of anesthetics on AERP and AF could be ruled out. 
Action potential recordings from canine right atrial trabeculae with the conventional microelectrode technique

The dogs from the in vivo AF studies were used. Following sedation (xylazine, $1 \mathrm{mg} / \mathrm{kg}$, i.v. and ketamine, $10 \mathrm{mg} / \mathrm{kg}$, i.v.) and anesthesia (pentobarbital, $30 \mathrm{mg} / \mathrm{kg}$ i.v.), the heart was rapidly removed through right lateral thoracotomy. The hearts were immediately rinsed in oxygenated modified Locke's solution containing (in $\mathrm{mM}$ ): $\mathrm{NaCl} 128.3, \mathrm{KCl} 4, \mathrm{CaCl}_{2}$ 1.8, $\mathrm{MgCl}_{2}$ 0.42, $\mathrm{NaHCO}_{3} 21.4$, and glucose 10 . The $\mathrm{pH}$ of this solution was set between 7.35 and 7.4 when saturated with the mixture of $95 \% \mathrm{O}_{2}$ and $5 \% \mathrm{CO}_{2}$ at $37{ }^{\circ} \mathrm{C}$. Isolated right atrial trabeculae were obtained and individually mounted in a tissue chamber with a volume of $50 \mathrm{ml}$. The preparations were stimulated through a pair of platinum electrodes in contact with the preparation using rectangular current pulses of $2 \mathrm{~ms}$ duration. The stimuli were delivered at a constant BCL of $500 \mathrm{~ms}$ for at least $60 \mathrm{~min}$ allowing the preparation to equilibrate before the measurements were initiated. Transmembrane potentials were recorded using conventional glass microelectrodes, filled with $3 \mathrm{M} \mathrm{KCl}$ and having tip resistances of 5-20 M $\Omega$, connected to the input of a high impedance electrometer (type 309, MDE Heidelberg GmbH, Heidelberg, Germany) which was coupled to a dual beam oscilloscope. The conduction time, maximum diastolic potential, action potential amplitude, and action potential duration measured at $25 \%, 50 \%$ and $90 \%$ of repolarization $\left(\mathrm{APD}_{25}, \mathrm{APD}_{50}\right.$ and $\mathrm{APD}_{90}$, respectively) were evaluated off-line using a custom made software running on an IBM compatible computer equipped with an ADA 3300 analogue-to-digital data acquisition board (Real Time Devices Inc., State Collage, PA, USA) having a maximum sampling frequency of $40 \mathrm{kHz}$. Stimulation with a constant BCL of $500 \mathrm{~ms}$ was applied during the course of the experiments. We aimed at maintaining the same impalement throughout each experiment, however, in case the impalement became dislodged, adjustment was performed and the experiment continued if AP characteristics of the re-established impalement deviated less than 5\% from the previous measurement.

Measurement of different ionic currents implicated in atrial fibrillation in the studies on the resveratrol derivative $\mathrm{Cl}$ 
The detailed characterization of the effects of resveratrol and its derivatives, C1-C4 and in more detail, of $\mathrm{C} 1$, on $\mathrm{I}_{\mathrm{Kur}}, \mathrm{I}_{\mathrm{K}, \mathrm{ACh}}, \mathrm{I}_{\mathrm{Na} \text {,peak }}$ and $\mathrm{I}_{\mathrm{Na} \text {,late }}$, as well as $\mathrm{I}_{\mathrm{Kr}}$ were performed by our colleagues in Canada. In brief, $\mathrm{K}_{\mathrm{v}} 1.5$, hERG and $\mathrm{Na}_{\mathrm{v}} 1.5$ currents were measured from tsA201 cells expressing the human heart genes encoding the $\mathrm{K}_{\mathrm{v}} 1.5, \mathrm{~K}_{\mathrm{v}} 11.2$ and $\mathrm{Na}_{\mathrm{v}} 1.5$ channels using the patch clamp technique in the whole cell configuration. Carbachol-induced $\mathrm{I}_{\mathrm{K}, \mathrm{ACh}}$ currents were measured in rat atrial cardiomyocytes.

\section{Cell shortening and calcium transient recordings}

Ventricular myocytes were prepared from adult Sprague-Dawley rats killed by an overdose of pentobarbital $(150 \mathrm{mg} / \mathrm{kg}$, i.p.). The hearts were removed and right ventricular myocytes were then obtained by enzymatic dissociation using standard protocols, which have been described previously by our group. Cell shortening by field stimulation and edge detection and calcium transients using the calcium-sensitive fluorescent probe Calcium Green-1AM were measured during standard procedures as published previously by our group.

\section{NFAT reporter assay}

Neonatal rat ventricular myocytes were isolated from the hearts of 1-3day-old neonatal rat pups and cultured for 40 hours. The cells were infected with Ad.GFP or Ad.NFAT-Luc-Promoter adenovirus. Cells were treated 24 $\mathrm{h}$ postinfection with vehicle or varying concentrations of $\mathrm{C} 1$ or resveratrol and/or angiotensin II $(1 \mu \mathrm{mol} / \mathrm{L}$ for $24 \mathrm{~h})$. Cells were harvested with the reporter lysis buffer supplied in the luciferase assay system kit (Promega, Madison, WI, USA) and luminescence according to the manufacturer's instructions.

\section{RESULTS}

\section{$1^{\text {st }}$ Aim}

In cooperation with and with the critical help of our colleagues (Dr. László Sághy, Dr. Róbert Pap) at the $2^{\text {nd }}$ Department of Internal Medicine and Cardiology Centre, University of Szeged, the large animal model of chronic atrial tachypacing induced atrial fibrillation was established in the 
In Vivo Electrophysiology Laboratory at the Department of Pharmacology and Pharmacotherapy, University of Szeged.

The author of this thesis played an essential role in the manual establishment of the large animal model of chronic atrial tachypacing induced $\mathrm{AF}$ in conscious dogs in the laboratory of his supervisor, participating in setting up the model as well as taking part in almost every pacemaker and pacemaker electrode implantation surgery for the studies performed in the laboratory of his supervisor.

\section{$2^{\text {nd }}$ Aim}

Effects of the $I_{K, A C h}$ blocker tertiapin-Q, the $I_{K r}$ blocker dofetilide and the $I_{N a}$ blocker propafenone on right atrial effective refractory period (AERP) in conscious dogs

Before the commencement of right atrial tachypacing, right AERP was $117 \pm 5.8$ and $127 \pm 6.4 \mathrm{~ms}$ in conscious dogs $(\mathrm{n}=6$; at basic cycle lengths of 150 and $300 \mathrm{~ms}$, respectively). Chronic rapid right atrial pacing markedly shortened right AERP. AERP was significantly and dose dependently prolonged by tertiapin-Q at both cycle legths, yielding the following values at $150 \mathrm{~ms}$ BCL: $82.3 \pm 1.48 \mathrm{~ms}$ in control vs. $93.3 \pm 3.33 \mathrm{~ms}(\mathrm{n}=6, \mathrm{p}<0.05)$ following $18 \mu \mathrm{g} / \mathrm{kg}$ and $106.7 \pm 2.11 \mathrm{~ms}(\mathrm{n}=6, \mathrm{p}<0.05)$ following $56 \mu \mathrm{g} / \mathrm{kg}$, respectively. The AERP was also significantly prolonged by dofetilide. Only the larger dose of propafenone increased AERP at the BCL of $150 \mathrm{~ms}$, while the AERP was significantly increased by both propafenone doses at the cycle length of $300 \mathrm{~ms}$.

Effects of tertiapin-Q, dofetilide and propafenone on burst-induced $A F$ in conscious dogs

Rapid right atrial bursts at $800 / \mathrm{min}$ did not induce any AF in any of the animals before the commencement of atrial tachypacing. Infusion of tertiapin-Q dose dependently and robustly reduced the incidence of right atrial burst induced AF $(90.2 \pm 1.89 \%$ in control vs. $12.4 \pm 8.69 \%$ following $18 \mu \mathrm{g} / \mathrm{kg}$ and $1.0 \pm 0.99 \%$ following $56 \mu \mathrm{g} / \mathrm{kg}$, respectively [n=6, all $\mathrm{p}<0.05])$, the total duration of $\mathrm{AF}\left(\log _{10}\right.$ total duration was $3.9 \pm 0.19$ in control vs. $1.9 \pm 8.69$ following $18 \mu \mathrm{g} / \mathrm{kg}$ and $0.3 \pm 0.23$ following 56 $\mu \mathrm{g} / \mathrm{kg}$, respectively $[\mathrm{n}=6$, all $\mathrm{p}<0.05])$ and the average duration of $\mathrm{AF}$ episodes ( $\log _{10}$ average duration was $2.3 \pm 0.25$ in control vs. $0.7 \pm 0.32$ in 
$18 \mu \mathrm{g} / \mathrm{kg}$ and $0.2 \pm 0.18$ in $56 \mu \mathrm{g} / \mathrm{kg}$, respectively [ $\mathrm{n}=6$, all $\mathrm{p}<0.05])$ in conscious dogs. The antiarrhythmic effect of tertiapin- $\mathrm{Q}$ was then compared to dofetilide and propafenone, both used in clinical settings for rhythm control in AF management. Both dofetilide and propafenone reduced AF incidence, the total duration of $\mathrm{AF}$ and the mean duration of $\mathrm{AF}$ episodes. These results clearly show that tertiapin-Q exhibits marked antiarrhythmic effect against AF in conscious dogs, and this effect seemed to be stronger than those of dofetilide and propafenone.

Effect of tertiapin-Q, dofetilide and propafenone on the QT interval in conscious dogs

Importantly, none of the investigated doses of tertiapin-Q prolonged the QT interval in conscious dogs, yielding $283.0 \pm 10.36 \mathrm{~ms}$ in control vs. $281.8 \pm 13.29 \mathrm{~ms}(\mathrm{n}=6, \mathrm{p}>0.05)$ following $18 \mu \mathrm{g} / \mathrm{kg}$ and $268.2 \pm 17.75 \mathrm{~ms}$ $(\mathrm{n}=6, \mathrm{p}>0.05)$ following $56 \mu \mathrm{g} / \mathrm{kg}$, respectively. Dofetilide $(25 \mu \mathrm{g} / \mathrm{kg})$ significantly prolonged the QT interval in conscious dogs, from $265.8 \pm$ $8.68 \mathrm{~ms}$ in control to $302.8 \pm 10.53 \mathrm{~ms}(\mathrm{n}=6, \mathrm{p}<0.05)$. Propafenone did not influence the duration of the QT interval.

Effects of tertiapin-Q, dofetilide and propafenone on action potentials in atrial trabeculae isolated from dogs with $A F$

Right atrial trabeculae were isolated from the dogs used for the in vivo AF studies, allowing wash-out of the last compound tested. All measurements were performed at the cycle length of $500 \mathrm{~ms}$. Tertiapin-Q significantly prolonged the action potential at all percentage of repolarization $\left(\mathrm{APD}_{25}\right.$, $\mathrm{APD}_{50}$ and $\left.\mathrm{APD}_{90}\right)$ in right atrial trabeculae from dogs with AF. Tertiapin-Q $(30 \mathrm{nM})$ did not influence conduction, action potential amplitude, diastolic potential. Dofetilide $(100 \mathrm{nM})$ significantly prolonged the action potential duration only at $90 \%$ of repolarization. Dofetilide did not alter conduction time, action potential amplitude, diastolic potential. Propafenone $(1 \mu \mathrm{M}) \mathrm{did}$ not prolong the atrial action potential, did not influence the action potential amplitude or diastolic potential but significantly increased conduction time.

The results of these studies are detailed in publications No. I and III. (Juhász et al., 2017; Jost et al. 2011).

$3^{\text {rd }}$ Aim 
Modulation of multiple ion channels and cellular pathways implicated in $A F$ : effects of Compound 1 (C1), a novel experimental compound

Drugs developed for AF management have been mostly targeted towards ion channels previously. However, structural and other, non-electric remodeling processes also contribute to the initiation and maintenance of AF. It has been suggested that targeting pathological remodeling in AF may also be useful for more effective management of AF. Based on the available data in the literature, an ideal anti-AF compound should exhibit the following effects: (i) $\mathrm{K}_{\mathrm{v}} 1.5$ ( $\mathrm{I}_{\mathrm{Kur}}$ ) inhibition in a frequency dependent manner; (ii) $\mathrm{I}_{\mathrm{K}, \mathrm{ACh}}$ block; (iii) $\mathrm{I}_{\mathrm{Na} \text {,late }}$ inhibition; (iv) lack of $\mathrm{I}_{\mathrm{Kr}}$ inhibition; (v) display atrial specificity: no effect on ventricular repolarization and on excitation-contraction (EC) coupling in ventricular tissue; (vi) antioxidant properties; (vii) NFAT inhibition. In this regard, a novel multifunctional small molecule, related to the structure of resveratrol, was developed at the University of Alberta and University of Manitoba, and was characterized and tested in cooperation with our group.

Effects of $\mathrm{Cl}$ and the parent molecule, resveratrol on different ionic currents implicated in atrial fibrillation

The inhibitory effects on $\mathrm{K}_{\mathrm{v}} 1.5$ currents of four novel resveratrol derivatives were compared to resveratrol. Resveratrol proved to be a weak inhibitor of $\mathrm{K}_{\mathrm{v}} 1.5$ currents $\left(\mathrm{IC}_{50}=66 \mu \mathrm{mol} / \mathrm{L}\right)$. Four resveratrol derivatives were synthesized, and $\mathrm{C} 1$ was the most potent blocker of $\mathrm{K}_{\mathrm{v}} 1.5\left(\mathrm{IC}_{50} \mathrm{~s}=\right.$ $0.36 \mu \mathrm{mol} / \mathrm{L}$ and $0.11 \mu \mathrm{mol} / \mathrm{L}$ for peak and late current inhibition, respectively). The other related compounds (C 2-4) displayed intermediate $\mathrm{K}_{\mathrm{v}} 1.5$ peak current inhibition $(8.3,10.9$ and $11.2 \mu \mathrm{mol} / \mathrm{L}$, respectively). Therefore, only $\mathrm{C} 1$ was selected for further studies. In single atrial cells isolated from rat hearts, $\mathrm{I}_{\mathrm{K}, \mathrm{ACh}}$ currents were induced by carbachol. $\mathrm{C} 1$ significantly inhibited carbachol-induced rat atrial $\mathrm{I}_{\mathrm{K}, \mathrm{ACh}}$ currents with an $\mathrm{IC}_{50}$ of $1.9 \mu \mathrm{mol} / \mathrm{L}$. To test the effects of $\mathrm{C} 1$ on the peak and late recombinant sodium current, $\mathrm{Na}_{\mathrm{v}} 1.5$ whole-cell currents were measured. 3 $\mu \mathrm{mol} / \mathrm{L} \mathrm{C} 1$ resulted in a $50 \%$ inhibition of peak current. To obtain concentration-response curves for peak and late $\mathrm{Na}_{\mathrm{v}} 1.5$ currents, cells were treated with the sea anemone toxin (ATX-II; $3 \mathrm{nmol} / \mathrm{L}$ ) to induce the latecurrent component and to test the inhibitory effects of $\mathrm{C} 1$ at different concentrations. $\mathrm{C} 1$ preferentially inhibited the late current when compared 
with peak current $\left(\mathrm{IC}_{50} \mathrm{~S}=1.1 \mu \mathrm{mol} / \mathrm{L}\right.$ vs. $3.2 \mu \mathrm{mol} / \mathrm{L}$, respectively). Inhibition of the hERG $\left(\mathrm{I}_{\mathrm{Kr}}, \mathrm{K}_{\mathrm{v}} 11.1\right)$ may result in arrhythmogenic QT prolongation, therefore, the effects of $\mathrm{C} 1$ on recombinant whole-cell hERG channel currents were tested. Construction of concentration-inhibition curves revealed that $\mathrm{C} 1$ was a weak inhibitor of peak and tail hERG currents with $\mathrm{IC}_{50} \mathrm{~s}$ of 30 and $25 \mu \mathrm{mol} / \mathrm{L}$, respectively, and these values were 100 -fold higher than those inhibiting peak and late $\mathrm{K}_{\mathrm{v}} 1.5$ currents.

The antioxidant and NFAT inhibitory effects of $\mathrm{Cl}$

Antioxidant therapy has been shown to reduce the incidence of postoperative AF in patients, and reactive oxygen species (ROS) also directly activate $\mathrm{K}_{\mathrm{v}} 1.5$ current. As resveratrol is a known antioxidant, we compared the antioxidant properties of $\mathrm{C} 1$ with resveratrol. At $10 \mu \mathrm{mol} / \mathrm{L}$, resveratrol and $\mathrm{C} 1$ displayed significant antioxidant effects $(0.59 \pm 0.04$ vs. $0.77 \pm 0.02$ of maximal DPPH $517 \mathrm{~nm}$ absorbance signal). At $100 \mu \mathrm{mol} / \mathrm{L}$, these values were $0.09 \pm 0.02$ and $0.19 \pm 0.02$ for resveratrol and $C 1$, respectively. It has been shown that resveratrol inhibits NFAT activation induced by phenylephrine contributing to a reduction in maladaptive hypertrophy in neonatal rat ventricular myocytes. Accordingly, we tested the effects of $\mathrm{C} 1$ on NFAT activation in these cells. Treatment with $0.01-25 \mu \mathrm{mol} / \mathrm{L}$ of $\mathrm{C} 1$ resulted in a significant reduction in NFAT activity when compared to no treatment. These results revealed that $\mathrm{C} 1$ significantly reduced NFAT activity at concentrations of $0.1 \mu \mathrm{mol} / \mathrm{L}$ and higher, with $1 \mu \mathrm{mol} / \mathrm{L}$ of $\mathrm{C} 1$ exhibiting half-maximal inhibition. $\mathrm{C} 1$ also significantly reduced Angiotensin-II-induced activation of NFAT.

Effects of $\mathrm{Cl}$ on right atrial effective refractory period (AERP) and atrial fibrillation in conscious dogs

Right atrial effective refractory period (AERP) measurements before the start of rapid atrial pacing at 400 beats/min yielded values of $118 \pm 3.7$ and $130 \pm 3.2 \mathrm{~ms}$ in conscious dogs $(\mathrm{n}=5$; at basic cycle lengths of 150 and 300 $\mathrm{ms}$, respectively). Rapid right atrial pacing for 6-7 weeks resulted in a significant decrease of right AERP, as AERP decreased below $80 \mathrm{~ms}$ in all five animals, and were defined as $79 \mathrm{~ms}$ for the following reason: the lower adjustable limit for S1-S2 intervals in the pacemakers available for this study was $80 \mathrm{~ms}$, therefore the exact AERP after 7 weeks of rapid atrial pacing and immediately before $\mathrm{C} 1$ administration could not be determined 
(measured AERP values were less than $80 \mathrm{~ms}$ in all dogs at both basic cycle lengths (BCLs) as an S1-S2 interval of $80 \mathrm{~ms}$ still evoked a $\mathrm{P}$ wave), although statistical comparison of AERP values was not possible. AERP measurements following $\mathrm{C} 1$ administration yielded $87.5 \pm 2.50 \mathrm{~ms}$ at 150 $\mathrm{ms}$ BCL in four animals (in one animal AERP was less than $80 \mathrm{~ms}$ ) and 90 $\pm 3.16 \mathrm{~ms}$ at $300 \mathrm{~ms} \mathrm{BCL}$, respectively, following $0.3 \mathrm{mg} / \mathrm{kg} \mathrm{C} 1$; and $90.0 \pm$ $3.16 \mathrm{~ms}$ at $150 \mathrm{~ms} \mathrm{BCL}, 100 \pm 3.16 \mathrm{~ms}$ at $300 \mathrm{~ms} \mathrm{BCL}$, respectively, following $1 \mathrm{mg} / \mathrm{kg} \mathrm{C} 1(\mathrm{n}=5$; with the exception of AERP measurement at $150 \mathrm{~ms}$ BCL following $0.3 \mathrm{mg} / \mathrm{kg} \mathrm{C} 1$ ). The incidence of $\mathrm{AF}$ was not influenced by administration of $\mathrm{C} 1(86.4 \pm 6.4 \%$ in control vs. $71.2 \pm 15.7 \%$ and $66.4 \pm 15.7 \%$ following 0.3 and $1 \mathrm{mg} / \mathrm{kg} \mathrm{C} 1$, respectively, both $\mathrm{p}>0.05$ ). However, the total duration of AF was significantly reduced by 1 $\mathrm{mg} / \mathrm{kg} \mathrm{C} 1$ administration and the average duration of AF episodes was also significantly decreased by $1 \mathrm{mg} / \mathrm{kg} \mathrm{C} 1$. These results clearly demonstrate in vivo efficacy of $\mathrm{C} 1$ against $\mathrm{AF}$ in conscious dogs. HPLC analysis of blood plasma collected within 5 min of i.v. bolus injection showed that we obtained concentration ranges of $0.32-0.79$ and $0.7-3.0 \mu \mathrm{mol} / \mathrm{L}$ for the 0.3 and $1 \mathrm{mg} / \mathrm{kg}$ doses, respectively. None of the investigated doses exhibited any QT interval prolonging effect in five conscious dogs, yielding $261.7 \pm$ $9.37 \mathrm{~ms}$ in control vs. $260.9 \pm 8.77 \mathrm{~ms}(\mathrm{p}=0.15)$ following $0.3 \mathrm{mg} / \mathrm{kg} \mathrm{C} 1$ and $257.3 \pm 9.05 \mathrm{~ms}(\mathrm{p}=0.55)$ following $1 \mathrm{mg} / \mathrm{kg} \mathrm{C} 1$.

The results of these studies are detailed in publication No. II. (Baczkó et al., 2014).

\section{DISCUSSION}

There is an unmet need for the safer and more efficacious pharmacological management of AF with compounds that lack ventricular cardiac electrophysiological proarrhythmic adverse effects. In the majority of in vivo studies characterizing drug candidates against $\mathrm{AF}$, animals anesthetized with volatile and/or intravenous anesthetics were used. These anesthetic agents have their own relatively well identified effects on cardiac ion channels that can significantly influence the results of these antiarrhythmic studies. In the work that serves as the basis for the thesis, the effects of the atrial selective $\mathrm{I}_{\mathrm{K}, \mathrm{ACh}}$ inhibitor tertiapin-Q, and the multichannel blocker $\mathrm{C} 1$ on $\mathrm{AF}$ were investigated in freely moving, 
conscious dogs, and the results were compared to those with dofetilide and propafenone, drugs used in the clinical setting for rhythm control in patients with AF. Also, for the first time, the effects of some of these compounds on atrial action potential configuration and parameters were compared in right atrial trabeculae isolated from dogs with chronic right atrial tachypacing induced AF. Rapid atrial pacing in dogs is an established large animal AF model where tachypacing leads to electrical and structural remodeling in the atria. In our studies, the electrical remodeling was monitored as the gradual decrease in AERP over the course of chronic tachypacing in our animals.

Atrial selective ion channel modulation and AF: effects of the $I_{K, A C h}$ blocker tertiapin- $Q$ on $A F$ and action potential configuration in remodeled atrial trabeculae

In our conscious in vivo canine AF model, tertiapin-Q markedly and dose dependently reduced the incidence of AF, the total and average duration of AF episodes, and this effect was paralleled by a significantly increased right AERP following acute intravenous tertiapin-Q administration. The significant prolongation by tertiapin-Q of the action potential duration at all percentages of repolarization was most likely responsible for the increased AERP in right atrial trabeculae isolated from these animals. Tertiapin-Q is a honey bee venom toxin peptide derivative that is a highly selective inhibitor of GIRK $\left(\mathrm{K}_{\mathrm{ir}} 3\right)$ channels carrying the acetylcholine-activated potassium current, $\mathrm{I}_{\mathrm{K}, \mathrm{ACh}}$. This channel is activated via muscarinic receptors following vagal stimulation leading to atrial action potential shortening and increased atrial dispersion of repolarization, suggesting an important role for this channel in creating an arrhythmia substrate for AF. Although $I_{K, A C h}$ downregulation was found in AF patients, a constitutively active component independent of muscarinic receptor activation was later identified in patients with chronic AF. In a dog model of atrial tachypacing induced AF, constitutive $I_{K, A C h}$ was also observed. Inhibition of $I_{K, A C h}$ by tertiapin-Q increased atrial action potential duration in atrial tachycardia-remodeled canine coronary-perfused left atrial preparations and decreased atrial tachycardia inducibility, similarly to the APD prolongation observed in right atrial trabeculae and the in vivo antiarrhythmic activity following tertiapin-Q application in our study. $\mathrm{I}_{\mathrm{K}, \mathrm{ACh}}$ inhibition proved to be beneficial in previous, other canine models of $\mathrm{AF}$ - like aconitine and vagal nerve 
stimulaton induced $\mathrm{AF}$, however, in these studies the effects of $\mathrm{I}_{\mathrm{K}, \mathrm{ACh}}$ inhibition were tested during isoflurane and/or combined isoflurane+thiopental anesthesia. Thiopental significantly prolonged AERP in a concentration dependent manner and caused an increase in atrial wavelength in guinea pig hearts, and isoflurane was found to have antifibrillatory effects in canine atria. Although $\mathrm{I}_{\mathrm{K}, \mathrm{ACh}}$ is also present in the ventricles, it is important to note that in conscious dogs tertiapin-Q did not prolong the QT interval in this study, suggesting that selective $\mathrm{I}_{\mathrm{K}, \mathrm{ACh}}$ block is unlikely to provoke ventricular arrhythmias based on repolarization prolongation.

In summary, we found that the selective $\mathrm{I}_{\mathrm{K}, \mathrm{ACh}}$ inhibitor tertiapin-Q significantly decreased the incidence of $\mathrm{AF}$, reduced the duration of $\mathrm{AF}$ episodes and prolonged atrial effective refractory period in conscious dogs with chronic right atrial tachypacing induced atrial remodeling. In this model, similar effects on AF and AERP were observed following the administration of the class IC antiarrhythmic drug propafenone, and the class III compound dofetilide, both used in the clinical management of AF. In right atrial trabeculae isolated from these dogs with $\mathrm{AF}$, atrial action potential durations were prolonged by tertiapin- $Q$ and dofetilide, but not by propafenone, which increased atrial conduction time. Importantly, tertiapinQ did not affect the QT interval, suggesting that the beneficial effects against $\mathrm{AF}$ are not accompanied by adverse effects on ventricular repolarization, therefore, selective $\mathrm{I}_{\mathrm{K}, \mathrm{ACh}}$ inhibitors may be promising atrial selective compounds in the future management of AF.

The other possible path for more efficacious AF management: the parallel modulation of multiple ion channels and cellular pathways implicated in AF - effects of C1, a novel compound related to resveratrol

Inhibition of the $\mathrm{I}_{\mathrm{Kur}} / \mathrm{K}_{\mathrm{v}} 1.5$ repolarizing potassium channel that is predominantly expressed in atria rather than the ventricles has been identified as an attractive therapeutic target in recent years. It was found that $\mathrm{C} 1$ was an effective inhibitor of this ion channel. The calculated $\mathrm{IC}_{50}$ values for $\mathrm{K}_{\mathrm{v}} 1.5$ channels were in the $0.11-0.36 \mu \mathrm{mol} / \mathrm{L}$ range for late and peak $\mathrm{K}_{\mathrm{v}} 1.5$ current inhibition, 180 - to 600 -fold lower than observed for the parent molecule, resveratrol $(66 \mu \mathrm{mol} / \mathrm{L})$. Inhibition of peak sodium current in a frequency-dependent manner may also be a useful strategy to manage 
AF by reducing the occurrence of premature action potentials and reduce the incidence of AF. Induction of the $\mathrm{Na}_{\mathrm{v}} 1.5$ late current may not only increase the risk of early after depolarization (EAD)-induced arrhythmias but also might lead to excessive sodium loading within cells that can promote chronic calcium loading, a primary trigger for EADs and calcineurin-mediated activation of the NFAT gene transcriptional pathway leading to pathological hypertrophic remodeling observed in chronic AF. Our results indicate that $\mathrm{C} 1$ inhibited peak and late components of recombinant human heart $\mathrm{Na}_{\mathrm{v}} 1.5$ currents more potently than resveratrol. $\mathrm{I}_{\mathrm{Kr}}$ (hERG) inhibition can lead to excessive action potential prolongation and serious TdP arrhythmias. Importantly, we observed that $\mathrm{C} 1$ was a weak inhibitor of hERG and it did not prolong the QT interval in conscious dogs. Investigations on cellular pathways implicated in $\mathrm{AF}$ generation and maintenance revealed that $\mathrm{C} 1$ maintained antioxidant and NFAT-inhibitory properties comparable to its parent molecule, resveratrol. In our in vivo conscious dog model with chronic atrial tachypacing induced atrial remodeling and atrial fibrillation, $\mathrm{C} 1$ increased AERP and significantly reduced the duration of $\mathrm{AF}$ episodes. These results provide in vivo evidence that $\mathrm{C} 1$ may be beneficial in the treatment of certain forms of $\mathrm{AF}$.

\section{CONCLUSIONS, NEW RESULTS AND THEIR POTENTIAL SIGNIFICANCE}

1. In cooperation with our clinician colleagues, the author of this thesis has played an key role in establishing a large animal model of chronic right atrial tachypacing induced atrial fibrillation. This model is suitable for the in vivo testing of novel drug candidates for the management of atrial fibrillation and also provides essential cardiac tissue for in vitro measurements aiming at the investigation of mechanisms responsible for $\mathrm{AF}$ initiation and maintenance.

2. We found that the selective $I_{K, A C h}$ inhibitor tertiapin-Q significantly decreased the incidence of AF, reduced the duration of AF episodes and prolonged atrial effective refractory period in conscious dogs with chronic right atrial tachypacing induced atrial remodeling. In this model, similar but somewhat less pronounced effects on AF and AERP were observed following the administration of the class IC antiarrhythmic 
drug propafenone, and the class III compound dofetilide, both used in the clinical management of AF. Importantly, tertiapin-Q did not affect the QT interval, suggesting that the beneficial effects against AF are not accompanied by adverse effects on ventricular repolarization, therefore, selective $\mathrm{I}_{\mathrm{K}, \mathrm{ACh}}$ inhibitors may be promising atrial selective compounds in the future management of AF.

3. In right atrial trabeculae isolated from dogs with $\mathrm{AF}$, atrial action potential durations were prolonged by tertiapin- $\mathrm{Q}$ and dofetilide, but not by propafenone, which increased atrial conduction time. The prolongation of repolarization and slowing of conduction would prevent or decrease atrial reentry following the administration of the investigated compounds.

4. A novel resveratrol derivative small molecule developed by our colleagues at the University of Alberta, Edmonton, Canada, exhibited in vivo efficacy in our conscious dog $\mathrm{AF}$ model and its effects were based on an advantageous combination of effects on multiple ion channels and cellular pathways implicated in $\mathrm{AF}$ generation and maintenance. Therefore, $\mathrm{C} 1$ can be a starting point for further development of compounds modulating multiple targets for improved pharmacological treatment of AF. 


\section{ACKNOWLEDGEMENTS}

I would like to express my sincere gratitude to Prof. Dr. András Varró, the director of the Department of Pharmacology and Pharmacotherapy, Faculty of Medicine, University of Szeged, for providing me the opportunity to carry out my research and teaching activities in his Department and I also thank him for his clear advice he offered whenever I had questions.

I am grateful to my supervisor, Dr. István Baczkó for his professional guidance throughout the years - since the writing and defense of my undergraduate thesis - and for systematically handing over the basics as well as novel information regarding the area of my research in an up-to-date fashion.

I thank Prof. Dr. Gyula Papp, academician, previous director of our Department, for his exemplary scientific and moral leadership he exhibits up to this day.

I thank Mária Győrfiné Kosztka for her excellent technical assistance and for her friendship. I offer my thanks to Katalin Tábori, Dr. Andrea Orosz, Dr. Tibor Hornyik, Dr. Zoltán Husti and Dr. Zoltán Márton, without whom the busy workdays would have been very hard to endure.

I sincerely thank Dr. László Sághy and Dr. Róbert Pap, electrophysiologists of the $2^{\text {nd }}$ Department of Internal Medicine and Cardiology Center, for offering outstanding professional advice and assistance to our laboratory during the establishment of the pacemaker implantation surgery techniques.

I thank Gábor Dobai and István Tajti animal care assistants for helping us to overcome the obstacles deriving from the nature of the chronic instrumented large animal model. I thank Gabriella Baczkó and Gabriella Vad for their assistance in administrative issues associated with my $\mathrm{PhD}$ studies. I acknowledge the support of all researchers, instructors and employees of the Department of Pharmacology and Pharmacotherapy.

To my Parents, my Brother, my Grandparents and my Friends.

\section{Financial support}

This work was supported by the National Research, Development and Innovation Office (NKFI-K119992 to A.V., NKFI-GINOP-2.3.2-15-201600040 to I.B.), and by the Hungarian Academy of Sciences. Salary support for Viktor Juhász was provided in part by grants TÁMOP-4.2.2/B-10/12010-0012; TÁMOP-4.2.2.A-11/1/KONV-2012-0035. 